D.O.I.: $10.3895 / \mathrm{S} 1808-04482009000100001$

\title{
TÉCNICAS DE GESTÃo DO SISTEMA TOYOTA DE PRODUÇÃO
}

\section{MANAGEMENT TECHNIQUES OF TOYOTA PRODUCTION SYSTEM}

\author{
Marcelo Augusto Oliveira da Justa ${ }^{1}$; Nilson Rodrigues Barreiros ${ }^{2}$ \\ ${ }^{1}$ Universidade Federal do Amazonas - UFAM - Manaus - Brasil \\ marcelo.justa@bol.com.br \\ ${ }^{2}$ Universidade Federal do Amazonas - UFAM - Manaus - Brasil \\ nilbarr@ufam.edu.br
}

\begin{abstract}
Resumo
Devido ao grande sucesso e resultados obtidos pela Toyota, inclusive com a recente liderança industrial que desbancou a poderosa General Motors - GM, estudos são realizados com o intuito de entender o modelo do Sistema Toyota de Produção - TPS que é hoje copiado pelas suas rivais, assim como também por empresas dos mais diferentes setores. Portanto, o objetivo que norteia esse artigo está na seguinte pergunta: quais as técnicas de gestão do sistema de gestão da Toyota?. A metodologia deste trabalho adota uma abordagem de pesquisa bibliográfia. Trata-se de uma análise da literatura sobre a evolução do TPS demonstrando algumas de suas principais técnicas de gestão. O resultado está na contribuição em compreender a construção da cultura organizacional da Toyota, a fim de direcionar uma caminho a ser seguido por outras empresas que desejam replicar o modelo de gestão. Conclui-se, portanto, que as técnicas gerenciais aqui apresentadas fazem parte de um conjunto de pressupostos básicos, necessários para a formação de uma filosofia que resulta em um sistema praticado e defendido por todas as pessoas da organização, pois somente através da interação das técnicas de gestão por meio das pessoas é que será possível replicar uma cultura semelhante a da Toyota.
\end{abstract}

Palavras-chave: sistema toyota de produção, manufatura enxuta, técnicas de gestão.

\section{Introdução}

Devido ao sucesso e resultados obtidos pela Toyota Motors Company, inclusive com a recente liderança industrial que ultrapassou a General Motors em quantidade de veículos produzidos, valor de mercado e lucro, estudos são realizados com o intuito de entender o segredo do sucesso da empresa que é hoje copiada pelos seus concorrentes, assim como também, por outras dos mais diferentes setores.

Ocorre que a diferença cada vez maior entre a Toyota e as outras companhias fez com que muitas perguntas surgissem. Dentre essas perguntas, a mais intrigante é "qual o segredo do sucesso da Toyota?". Portanto, o desafio das empresas, desde então, é copiar o modelo na tentativa de 
alcançar os mesmos resultados e transformar as operações de produção em uma vantagem competitiva com o intuito de sobreviver a acirrada disputa global, através da redução dos custos e, ao mesmo tempo, da produção de pequenas quantidades de muitos tipos de produtos.

Porter (1999) ratifica que essa iniciativa das empresas em melhorar a qualidade com custos menores é forçada pelas exigências dos clientes e pela competitividade global, pois, para competir com eficácia neste ambiente altamente competitivo, as empresas devem continuamente inovar e buscar aprimoramento contínuo das vantagens competitivas. Nesse contexto, a Toyota desponta como liderança global em obter melhores resultados com o menor custo, pois, realmente transformou a operação em um diferencial competitivo e estratégico baseado em ferramentas e métodos de melhoria continua da manufatura.

O chamado Toyota Production System - TPS ou ainda, Sistema Toyota de Produção, vem sendo aclamado como a origem do espetacular desempenho da Toyota como fabricante. Desta forma, o estudo procura contribuir com algumas constatações observadas por meio do estudo de alguns dos autores mais renomados sobre o tema.

O objetivo está na tentativa de responder a seguinte questão: quais os segredos do sistema de gestão mais copiado da atualidade?. Portanto, o estudo contribui com uma descrição do jeito de ser da empresa Toyota, bem como a forma de gerir o grande sucesso da mesma. Outrossim, um esclarecimento para as outras empresas que desejam replicar a mesma filosofia e técnicas de gestão do TPS para a construção de cultura organizacional.

\section{Metodologia}

O presente artigo realiza uma análise da pesquisa bibliográfica realizada em literaturas que abordam sobre o modelo de gestão da Toyota, principalmente sobre o livro de Jeff Liker que descreve os princípios do modelo de gestão. O objetivo é esclarecer uma das dúvidas mais frequentes sobre quais as principais técnicas de gestão que a empresa adota em seu famoso Sistema Toyota de Produção.

Neste contexto, as revisões da literatura se apresentam como uma atividade importante para identificar e conhecer uma determinada área do conhecimento (NORONHA; FERREIRA, 2000), além de permitir a cobertura de uma gama de fenômenos geralmente mais ampla do que aquela que poderia ser pesquisada diretamente (GIL, 1996). Além disso, as revisões permitem a identificação de perspectivas para pesquisas futuras, contribuindo com sugestões de idéias para o desenvolvimento de novos projetos de pesquisa (NORONHA; FERREIRA, 2000).

Primeiramente, estuda-se a origem do TPS e a forma como seus criadores questionam o antigo paradigma criado por Ford. Logo após, faz-se uma análise de como esse modelo migrou para as empresas ocidentais, tornando-se uma dos sistemas mais copiados atualmente. 
Procura-se também extrair da literatura as técnicas gerenciais que transformaram o modelo em uma filosofia de trabalho, no qual a Toyota faz uso para transformar as operações em vantagem competitiva. Neste contexto, compreende-se como ocorrem a interação destas com as pessoas e as outras partes interessadas, tais como o cliente.

Compreende-se como construir uma cultura organizacional voltada para a eliminação daquilo que não agrega valor, reduzindo estoques, transformando o comportamento dos lideres e liderados para uma participação ativa na solução de problemas, na padronização, na redução de custos e na inovação, portanto, na melhoria contínua.

\section{A evolução do TPS}

O TPS surgiu de um estudo realizado por Eiji Toyoda juntamente com seu principal engenheiro de produção Taiichi Ohno sobre outro modelo já existente aplicado na fábrica da Ford, até então a unidade mais eficiente e complexa do mundo. O modelo de produção em massa, criado por Henry Ford, contrapôs o antigo modelo de produção que construía centenas de automóveis por ano, todos eles fabricados pelo clássico sistema artesanal. Nesse período, o volume de produção era muito baixo quando comparado aos dias atuais. Produzia-se cerca de mil carros por ano e, dificilmente, seriam encontrados dois carros idênticos (WOMACK; JONES; ROOS, 1992).

Durante as visitas as fábricas da Ford para estudar o modelo de produção em massa, Toyoda e Ohno perceberam que o pequeno mercado e com demandas fragmentadas não iria suportar altos volumes de produção. Portanto, para sobreviver, os gerentes perceberam que era necessário fazer uma adaptação ao mercado japonês, isto é, um contraste a filosofia Ford da época, eram necessários baixos volumes e com diferentes modelos usando a mesma linha de montagem. A necessidade do mercado japonês exigia qualidade, custo baixo, lead-time curto e flexibilidade (OHNO, 1997).

Ainda nas visitas de estudo as fabricas americanas, em 1950, os gerentes da Toyota observaram muitos equipamentos produzindo grandes quantidades e formando estoques que seriam transferidos para outro processo e assim por diante. Esse tipo de processo causava o acumulo de estoques intermediários decorrente do excesso de produção e defeitos escondidos em grandes lotes acumulados por semanas (OHNO, 1997).

$\mathrm{O}$ autor revela que por meio do benchmarking realizado nas visitas a Ford, a Toyota aproveitou a linha de montagem contínua da Ford, porém, implementando a melhoria de redução dos desperdícios. Estabeleceu-se também a produção puxada conforme a necessidade do cliente, inspirado nos supermercados que abasteciam as prateleiras somente após a necessidade do produto na mesma, e o fluxo contínuo com o one-piece-flow - fluxo puxado um a um. Com o sistema Just in Time, pode-se reduzir drasticamente os estoques vistos nas fabricas da Ford, através de um alerta 
visual que indicava ao processo anterior quando era necessária a reposição do produto. Alerta este chamado de Kanban (significado de cartão).

$\mathrm{O}$ autor também revela que os gerentes começaram a usar um método para solucionar problemas chamado de PDCA (Plan - planejar; Do - fazer; Check - verificar/controlar; Act - agir) que é um dos pilares da melhoria continua. O termo japonês para a melhoria contínua é o Kaizen que faz uso do trabalho em equipes para a solução de problemas, documentando e melhorando processos, coletando e analisando dados. Portanto, o TPS agora é uma filosofia não só para a Toyota e sim para todos os componentes que compõem o sistema de negócio Toyota na Supply Chain (cadeia de abastecimento).

Para Ohno (1997), o benchmarking com as empresas americanas foi o primeiro passo da Toyota para entender os processos, as atividades e as estratégias dos competidores, reconhecendo seu impacto na própria cultura organizacional e principalmente promovendo melhorias no sistema interno com intuito de fazer as adaptações necessárias a própria realidade. Atualmente, a Toyota está sempre pensando em ensinar e reforçar o sistema de valores que os fundadores deixaram, tais como o botar a mão na massa, inovação e atuar na causa raiz dos problemas baseado em fatos. Este é o legado e a filosofia da família Toyota.

Segundo Womack et al (1992), atualmente se usa o termo Lean Manufacturing que significa Manufatura Enxuta - ME, o qual foi cunhado no livro ‘A Máquina que Mudou o Mundo' que trata de um amplo estudo sobre o TPS. Os autores popularizaram esse termo no ocidente por meio dos resultados de uma pesquisa realizada pelo Massachusetts Institute of Technology - MIT sobre uma descrição abrangente de todo o sistema de negócios da Toyota, desenvolvimento de produtos, gerenciamento de suprimentos, relações com os consumidores, atendimento dos pedidos desde a matéria prima até a produção e o gerenciamento de toda a empresa. A partir da publicação do estudo no MIT, o Lean tem sido o modelo de gestão escolhido pelas empresas que tentam implantar em suas fábricas as mesmas práticas diferenciadas do TPS, a fim de atingir os mesmos níveis de desempenho da Toyota.

Womack e Jones (2004) afirmam que coexistem várias definições para a ME. Os autores, por exemplo, definem a ME como uma abordagem que busca uma forma melhor de organizar e gerenciar os relacionamentos de uma empresa com seus clientes, cadeia de fornecedores, desenvolvimento de produtos e operações de produção, segundo a qual é possível fazer cada vez mais com menos (menor quantidade de equipamento, menor esforço humano, menor tempo, menor custo, etc.).

Para Shah e Ward (2002), a abordagem da ME engloba uma ampla variedade de práticas gerenciais, incluindo just in time, sistemas de qualidade, manufatura celular, entre outros. Shingo 
(1996) confirma o poder do TPS através de uma analogia, o qual afirma que o modelo de gestão é tão poderoso que poderia extrair água torcendo uma toalha seca.

\section{Uma arma estratégica para a competitividade}

Segundo Liker (2005), o sucesso da Toyota proporcionou uma reputação de qualidade percebida pelos clientes, isto é, as pessoas podiam confiar que um automóvel Toyota iria funcionar bem na primeira vez e continuar operando continuamente sem apresentar problemas. Essa reputação só foi possível devido a transformação da operação em um diferencial competitivo e estratégico baseado em ferramentas e métodos de melhoria continua na manufatura, tais como: just in time JIT, JIDOKA - autonomação, Kaizen, fluxo continuo, e outras mais. Essas técnicas ajudaram a implementar a revolução da produção enxuta.

O autor afirma que apesar da grande influência do sistema de produção enxuta, muitos dos concorrentes implementaram o TPS apenas superficialmente, isto é, a maioria das empresas focou apenas em ferramentas como o 5s (sensos de utilização, organização, limpeza, padronização e autodisciplina) e o just-in-time, sem entender por completo o TPS que deve estar inserido na cultura organizacional. Outra falha que ocorre na maioria das empresas é o não envolvimento da alta administração nas operações do dia-a-dia e na melhoria continua que é fundamental para o sucesso da filosofia.

O autor também ressalta que ter uma produção enxuta requer uma forma de pensar diferente com o foco em fazer o produto fluir por um processo contínuo que agrega valor ao cliente interno e externo e sem interrupções. Um sistema "puxado" que retorna em cascada da demanda do cliente, que por sua vez, puxa somente o que necessita e quando precisa. Uma cultura em que todas as pessoas, em todos os níveis, estão comprometidas com a melhoria continua.

Para Liker (2005), a Toyota descobriu que a chave para a operação era a flexibilidade, isto é, quando você trabalha com lead-times menores e com linhas de produção flexíveis, pode-se obter maior qualidade, maior resposta do cliente, maior produtividade e melhor utilização dos equipamentos e espaço. A Toyota, ainda nos anos 40s e 50s focou na eliminação do desperdício do tempo e material de cada etapa do processo produtivo, desde a entrada da matéria prima até o produto acabado.

Segundo Ohno (1997), o modelo do TPS está baseado nos chamados 4Ps: Philosophy filosofia, Process - processo, People and Partness - pessoas e parceiros e Problems Solve - solução de problemas. O problema é que grande parte das empresas pensam que estão trabalhando de acordo com o modelo do TPS, contudo, constata-se que elas apenas estão focando o "P" do processo e esquecendo de desenvolver os outros Ps. 
O autor revela que muitos críticos descrevem a Toyota como uma empresa chata "Boring Company", porém os resultados de qualidade, lucratividade, reputação de melhor fabricante no mundo, acabam tornando as críticas irrelevantes. O fato é que o TPS trouxe para a Toyota melhorias incríveis para a eficácia e estabilidade do negócio por meio de técnicas de gestão próprias da Toyota, no qual proporcionou o desenvolvimento de uma cultura voltada para a melhoria contínua por meio do envolvimento total das pessoas.

\section{As técnicas de gestão}

\subsection{Os desperdícios}

Segundo Ohno (1997), o TPS está baseado nos princípios da cultura de melhoria contínua e da redução dos custos. O autor estabelece como passo preliminar para a aplicação do TPS a identificação e eliminação dos desperdícios que necessita de tempo no chão de fabrica para aprender a mapear as atividades de processo que agregam valor e as que não agregam valor ao produto.

Liker (2005) corrobora com Ohno afirmando que o primeiro passo é examinar o processo a partir da perspectiva do cliente interno e externo. O mesmo identifica oito tipos de desperdício que não agregam valor ao negócio, são eles: excesso de produção, tempo de espera (operador ou máquina), transporte desnecessários, excesso de processos ou processos incorretos, excesso de estoque (matéria prima, semi-acabados e/ou acabados), movimento humano desnecessário, defeitos e suas conseqüências, subutilização de mão-de-obra. A Toyota considera o excesso de produção a origem para os demais desperdícios.

$\mathrm{O}$ autor ressalta que atualmente os desperdícios são os males que mais prejudicam a sobrevivência das empresas frente à competitividade, seja na indústria, na de construção civil, na agricultura e também no governo. O desperdício é tudo aquilo que consome algum tipo de recurso, porém não agrega qualquer valor ao processo, portanto, para se obter lucro, continuar sobrevivendo e empregando, a inexistência de desperdícios nas empresas é a meta a ser atingida a todo custo.

Para Liker (2005), os desperdícios se escondem por toda parte na produção. Para evitar isso, deve-se compreender por completo o que é o desperdício e suas causas. Todos os desperdícios se tornam parte dos custos diretos e indiretos, portanto, são pontos relevantes na busca pela redução de custos.

Ao pensar sobre a eliminação total do desperdício, tenha em mente que o aumento da eficiência só faz sentido quando está associado á redução de custos. Para obter isso é necessário começar a produzir apenas aquilo que se necessita usando um mínimo de mão-de-obra. Observe a eficiência de cada operador e de cada linha. Observe então os operadores como um grupo, e depois 
a eficiência em todas as linhas. A eficiência deve ser melhorada em cada estágio e, ao mesmo tempo, para a fábrica como um todo. A verdadeira melhoria na eficiência surge quando se produz zero desperdício e se eleva a porcentagem de trabalho para cem porcento.

Segundo Liker (2005), um processo adequado irá produzir o correto resultado. Um bom começo para uma empresa eliminar desperdícios é criar fluxo contínuo nos processos de manufatura. O fluxo contínuo tende a forçar a implementação de várias outras ferramentas do TPS, isto é, baixando o nível de estoque iremos tornar visíveis os problemas, portanto, dispara-se uma ação para resolvê-los e não somente escondê-los.

$\mathrm{O}$ autor ressalta que criar um fluxo contínuo significa juntar operações que antes eram separadas, portanto, quando operações são juntas há mais trabalho em equipe, o feedback é mais rápido para os problemas de qualidade, o processo é melhor controlado e as pessoas responsáveis pela solução dos problemas são acionadas imediatamente.

$\mathrm{Na}$ medida do possível, deve-se racionalizar os fluxos de fabricação entre processos de forma contínua, otimizando e aproveitando os espaços disponíveis, a fim de minimizar a movimentação de pessoas, produtos, materiais e documentos. É necessário estabelecer um fluxo racional de trabalho. Quando são aprimorados os processos e elevados os níveis de capacitação e motivação dos empregados, os índices de desperdício caem naturalmente. Nunca se deve considerar que já se atingiu um nível de qualidade suficiente, que permita a acomodação. É preciso buscar a melhoria continuamente (LIKER, 2005).

\subsection{Perfil da liderança}

Segundo Liker (2005), o contraste entre os grandes executivos da Toyota e os de outras empresas, está no fato de que os lideres dos concorrentes não se tornaram Chief Executive Officer CEO devido aos progressos e promoções internas, pelo contrário, eles abruptamente vieram de fora para mudar a cultura organizacional, mexer e mudar a direção das empresas que estavam indo mal. O fato é que muitas empresas alternam entre o sucesso extremo e a fronteira da falência. A solução encontrada para estes casos é trazer novos CEOs que irão conduzir a empresa para uma mudança radical de direção.

Contrariando essa atitude de procurar talentos fora da empresa, a Toyota desenvolve os seus CEOs internamente, isto é, há um progresso e promoção dos lideres através de uma preparação sempre acompanhada por um mentor que promove todo o ensino da teoria básica do TPS e os princípios da filosofia Toyota. Durante toda a história da Toyota, os lideres foram encontrados dentro da empresa, no tempo certo para dar continuidade ao próximo passo da evolução, portanto, eles já estavam lá no departamento de vendas, desenvolvimento, manufatura, design, etc. Contudo, apesar das diferenças pessoais do estilo da gestão, nenhum desses lideres se desviou da filosofia 
básica do TPS, portanto, a Toyota sempre tem um líder preparado para ocupar um posto executivo que realmente entendem o trabalho, praticam a filosofia e ensinam outros (LIKER, 2005).

$\mathrm{O}$ autor ainda ressalta outro ponto importante que é a capacidade dos lideres conseguirem manter a cultura anos após anos, criando um ambiente de aprendizado contínuo em toda a organização, isto é, não há a possibilidade de cada líder criar a sua própria cultura transformando a empresa em algo superficial onde não há o desenvolvimento real de lealdade nós funcionários. $\mathrm{O}$ líder Toyota vai até o chão de fábrica e realmente procura entender a situação atual do nível operacional. Liderar não é somente gerenciar a tecnologia ou as tarefas, é necessário desenvolver a cultura. Liderar é demonstrar comprometimento com a qualidade todos os dias, mostrando também que a qualidade vem primeiro nos níveis estratégicos e depois é desdobrada até o operacional. A raiz da liderança Toyota está em desenvolver outros lideres a entender o trabalho, viver a filosofia e ensinar a outros. Uma frase comum na Toyota diz: Antes de construirmos carros, nós construímos pessoas.

Para Liker (2005), o verdadeiro líder motiva e desenvolve seus funcionários capacitando-os para agir por conta própria, atribuindo-lhes tarefas críticas para o sucesso da empresa, permitindolhes exercer com liberdade e autonomia sem temer a competição interna. O verdadeiro líder entende que o sucesso de si próprio depende do sucesso de seus colaboradores. O verdadeiro líder exerce a liderança pelo exemplo. Não existe um único estilo ou característica de liderança valida para toda e qualquer situação. Cada tipo de situação requer um tipo de liderança diferente para se alcançar a eficácia dos colaboradores.

O sucesso a longo prazo reside na capacidade de fazer as coisas importantes de forma melhor que os concorrentes. E para isso as pessoas podem ajudar bastante, mais do que as empresas poderiam imaginar e muito mais do que as próprias pessoas poderiam sequer pensar. As pessoas formam a base fundamental de toda a qualidade e produtividade da empresa. São elas que fazem a diferença. Para isso, torna-se necessária uma administração participativa, que compartilha e que estimula a criatividade e a inovação. Saber como gerenciar as pessoas é o desafio de todo gerente ou, mais do que isso, saber como gerenciar com as pessoas.

\subsection{0 trabalho em equipe}

Segundo Liker (2005), muitas empresas possuem experiência com grupos de trabalho que focavam apenas no auxílio de emergência a produção, inspeção de qualidade e reparos. Quando não ocorrem problemas imediatos e incêndio para apagar, elas vão para a sala de reunião apenas para uma pausa do trabalho. O que essas empresas estão perdendo é obvio, elas não têm o TPS e a cultura inserida nas pessoas. 
O autor ressalta que não se deve implantar times de trabalho sem antes desenvolver um forte trabalho de implementação do sistema e cultura necessários para o sucesso e o suporte, pelo qual os times criam idéias que agregam valor. Construir uma cultura TPS irá levar algum tempo, contudo, também depende de um correto programa de motivação fundamentado nas necessidades das pessoas. As pessoas precisam ter um grau de segurança para que possam perceber que elas pertencem a um time. É necessário também criar tarefas desafiadoras e dar alguma autonomia para que elas possam sentir que têm o controle sobre as tarefas que executam. Também é necessário medir e dar feedback do progresso e por ultimo, o reconhecimento.

Para Liker (2005), o contrário do que se supõe normalmente nas empresas, os erros são muito mais de responsabilidade das chefias que simples descuido ou indolência do pessoal operacional. Notoriamente, verifica-se que as causas estão na maioria absoluta dos casos relacionadas a falta de método de trabalho, método inadequado de trabalho ou falta de treinamento no método. Na verdade, o que se revela ao implantar equipes de trabalho, é que as pessoas gostam, apreciam e têm grande orgulho em fazer corretamente o seu trabalho e se decepcionam quando este não apresenta os resultados esperados. As pessoas somente deixam de desempenhar corretamente o serviço quando uma das três condições mencionadas ocorrem.

$\mathrm{O}$ autor afirma que as pessoas apreciam e buscam a satisfação do trabalho bem feito, tornando-se muito fácil mobilizar a equipe para contribuir para um processo de melhoria, através da identificação das causas e da criação de mecanismos necessários para que as falhas e erros não tornem a ocorrer. Desta forma, temos um duplo efeito benéfico que além de contribuírem para a solução dos problemas da empresa ou organização, os funcionários também passam a se sentirem mais satisfeitos, o que os torna mais produtivos e mais interessados em contribuir, num círculo virtuoso em que todos ganham, e que se acelera continuamente.

A grande vantagem do trabalho em grupo é que todas as pessoas possuem pontos fortes e pontos fracos, no qual um componente mais fraco poderá ter o suporte de um colega mais forte. Em um grupo, tem-se a oportunidade de intercâmbio de idéias, de tal sorte que a equipe tem uma grande chance de crescer e vencer os obstáculos.

Segundo Liker (2005), o processo produtivo deve ser observado sem preconceitos e com a mente limpa. Repita a pergunta “por que?” cinco vezes para cada problema encontrado. A única forma de constatar o funcionamento do TPS no chão de fábrica é ver in loco e questionar: as instruções de trabalho estão sendo seguidas?, o trabalho está em fluxo contínuo e com o JIT?. É necessário observar pessoalmente o fluxo de material na linha e responder a estas perguntas e também ver se os operadores estão pedindo ajuda e parando a linha caso seja necessário. Também se faz necessário uma ultima pergunta: como as áreas de suporte estão respondendo aos chamados de ajuda da produção?. 
O autor alerta que gráficos e números podem medir resultados, porém, eles não revelam os detalhes acontecidos e seguidos no processo atual no dia-a-dia. O que a Toyota solicita de seus colaboradores e gerentes é um profundo entendimento do fluxo de processo, assim como também a habilidade de avaliar criticamente e analisar o que está acontecendo. Além de saber como ir até a causa raiz do problema e comunicar de forma efetiva aos outros.

Para Liker (2005), o acompanhamento do processo de trabalho deve ser efetivado no próprio local onde ele é realizado, deve-se mapeá-lo, fazer perguntas, anotar respostas, observar e finalmente, se for possível, tomar o lugar do operador e fazer o trabalho. Só assim será possível compreender bem a natureza e a extensão do fluxo de processo e coletar dados significativos para o entendimento e melhoramento total da operação.

Segundo Liker (2005), é necessário praticar o empowerment (investir de poder os funcionários) para que eles possam sinalizar e parar a linha de produção quando detectado um problema, antes que esse problema continue para o processo posterior. Deve-se também criar uma cultura de fazer certo da primeira vez. A idéia central é trazer os problemas para a superfície e torná-los aparente para que se tomem as contramedidas imediatamente. Deve-se usar os Poka-Yoke (dispositivos a prova de erros) ao máximo para evitar erros. Esses dispositivos criativos tornam impossível ao operador o erro operacional.

O autor ressalta que a cultura não é algo que se manipule facilmente. A cultura só muda depois que você tiver alterado com sucesso as ações das pessoas e depois que o novo comportamento produzir alguma vantagem nas pessoas por algum tempo. A mudança numa cultura organizacional é quase sempre uma mudança de paradigmas.

Para Liker (2005), os defeitos são resultados de erros. A ferramenta do Poka-Yoke é um meio de se evitar o erro com o uso de dispositivos de controle. O ponto mais importante para evitar que defeitos sejam construídos no processo é tornar conscientes os operadores de que eles são os controladores da qualidade, eles devem ser encorajados a parar o processo e tomar providencias quando descobrir que há imperfeições na fabricação.

\subsection{A produção puxada}

Segundo Liker (2005), a filosofia do TPS não é administrar estoques, e sim eliminá-los. Desde o começo, a Toyota pensou em puxar o necessário baseado na necessidade do cliente, contrariando o velho sistema que empurra. Puxar significa o estado ideal da manufatura just in time, dando ao cliente o que ele realmente quer, quando quer e na quantidade que ele necessita.

$\mathrm{O}$ autor ressalta que para minimizar as trocas de equipamento, os set-ups, que são necessários para fazer diferentes tipos de produtos com o mesmo equipamento, deve-se manter um buffer (pequenos estoques). Sinais visíveis foram desenvolvidos para controlar e manter o nível 
desses pequenos lotes tais como: cartões, caixas vazias, carrinhos vazios, etc. Esses sinais visuais são chamados de Kanban (cartão).

Entende-se melhor o real significado do Just in Time comparando-o com seu antecessor, o Just in Case - JIC. A gestão de um negócio pela ótica do JIC conduz a que se produza segundo a máxima capacidade de produção dos recursos, antecipando a demanda futura sob a forma de estoques. Não se desenvolvem esforços nem para balancear as capacidades nem para eliminar as variabilidades, pois o interesse é operar o tempo todo na máxima capacidade (LIKER, 2005).

Para Liker (2005), o ritmo de produção é ditado pela capacidade excessiva do primeiro processo, que "empurra" a produção em direção aos processos sucessivos, resultando inventário consideravelmente mais alto do que o necessário. Já o JIT gerencia para obter o nivelamento da produção e age para diminuir as variabilidades no processo. Atribui-se pequenos estoques de material em processo na frente de cada centro produtivo, para proteger o sistema das incertezas e flutuações estatísticas dos processos de manufatura.

Atingindo-se este estoque, o processo precedente é interrompido. Ao se considerar toda a cadeia produtiva, o JIT mantém uma quantidade de estoques intermediários bastante inferiores ao JIC. Através de ferramentas e técnicas de solução de problemas, busca-se a melhoria contínua de seus processos e procedimentos através da eliminação de todo o desperdício. O JIT não é apenas um método de aperfeiçoamento do processo de manufatura, mas um diferente método de gerenciar a produção. O JIT expõe problemas e elimina tudo o que não agrega valor ao produto (LIKER, 2005).

Segundo Liker (2005), infelizmente alguns clientes são imprevisíveis e os pedidos variam significativamente de semana para semana, de mês para mês. Se a produção ocorrer conforme os pedidos, pode-se produzir grandes quantidades na semana, pagando hora extra, e estressando as pessoas e equipamentos, porém, se os pedidos são reduzidos drasticamente na outra semana, as pessoas e equipamentos ficarão ociosas e também não se saberá quanto comprar dos fornecedores.

Portanto, será necessário estocar uma quantidade que possivelmente cada cliente poderá solicitar. Desta forma é impossível desenvolver uma operação enxuta. A Toyota descobriu que para criar uma operação enxuta e dar aos clientes um melhor serviço e melhor qualidade é necessário nivelar o plano de produção, isto é, pegar o volume total de pedidos em um determinado período e nivelá-los para uma mesma quantidade e mix a serem feitas em cada dia (LIKER, 2005).

Para Liker (2005), há 4 benefícios em nivelar o plano de produção: flexibilidade em fazer o que o cliente quer e quando quer; redução do risco de produtos não vendidos; balanceamento do uso de mão-de-obra e nivelamento da demanda para o processo e para os fornecedores. Entretanto, para satisfazer os clientes que possuem uma demanda com significante flutuação, recomenda-se manter um mínimo possível de estoque. Isso parece até contrariar o pensamento do processo enxuto, 
porém, é uma forma de proteger o cliente de um possível pico de demanda. Da mesma forma, podese aplicar também para o fornecedor.

O autor ressalta que em alguns casos é necessário manter uma combinação de ambas as situações. A questão é como podemos acomodar o desejo do cliente, atender as suas diferentes escolhas e ter o produto pronto rapidamente sem comprometer a integridade do sistema de produção. A cultura TPS não permite aos gerentes dizer que "nós não podemos fazer". A situação deve ser estudada, experimentada no chão de fábrica e implementada.

Para manter a diversificação do mercado e o nivelamento da produção em harmonia, é importante evitar o uso de instalações e equipamentos dedicados que poderiam ter maior utilidade geral. É preciso maior esforço para encontrar as instalações e equipamentos mínimos necessários para uso geral. É normal quando as coisas nem sempre acontecem de acordo com o planejado, mas existem pessoas no mundo que precipitadamente tentam forçar uma programação mesmo sabendo que ela possa ser impossível. Elas dirão "é bom seguir a programação" ou "é uma pena mudar o plano" e farão qualquer coisa para fazê-lo funcionar. Mas, como não se pode prever o futuro com exatidão, as ações devem mudar e se adaptar a situações mutantes. É importante capacitar as pessoas para lidar com as mudanças e a pensar flexivelmente (LIKER, 2005).

\subsection{Controle visual e trabalho padronizado}

Segundo Liker (2005), a tarefa mais crítica quando implementamos a padronização é achar o meio termo entre prover aos funcionários rígidos procedimentos a serem seguidos e ao mesmo tempo dar a liberdade para que eles possam inovar e ser criativos para contribuir com os objetivos de custo, qualidade e entrega.

$\mathrm{O}$ autor ressalta que os primeiros padrões e instruções devem ser específicos o suficiente para serem guias úteis, e ainda generalistas o suficiente para permitir a flexibilidade e o fácil entendimento para qualquer pessoa que irá usá-lo. É importante utilizar as idéias dos próprios funcionários para aprimorar as instruções de trabalho, dando a oportunidade para que eles possam contribuir para a melhoria contínua no processo.

As pessoas desejam poder assumir a responsabilidade por seus próprios recursos. Querem sentir que estão dando uma contribuição pessoal para algo importante. É assim que se consegue a verdadeira motivação e a verdadeira administração participativa. As variações, erros ou desvios devem ser corrigidos para que as operações sejam normalizadas. A padronização visa manter o desempenho dentro do nível pré-estabelecido e também assegurar que tudo seja feito exatamente de acordo com o que se pretendia fazer (LIKER, 2005).

Segundo Liker (2005), O controle visual é qualquer meio de comunicação usado no ambiente de trabalho que mostra rapidamente como o trabalho deve ser ou está desviado do padrão 
ou meta estabelecida. Também ajuda os funcionários a fazer o trabalho de forma correta e igual ao procedimento padrão a ser seguido no processo de trabalho.

Para Liker (2005), os controles visuais também incluem os desvios entre a meta e o realizado exibidos sob forma gráfica, onde são fixados em local publico e de fácil visualização. A grande questão a ser observada é possibilidade de andar pela empresa e reconhecer que o padrão de trabalho, procedimentos e metas estão sendo seguidos e alcançados.

O autor ressalta que nas linhas de produção, o uso dos controles visuais, ou gerenciamento pela visão, torna-se obrigatório. Portanto, é necessário estabelecer um processo padronizado pelos quais as condições atuais se tornam rapidamente visíveis no local de trabalho permitindo que todos os funcionários visualizem imediatamente a situação normal ou anormal, bem como reconheçam a situação e tomem ações para retornar à condição padrão.

\section{Resultados}

O estudo do jeito de ser da Toyota demonstra que a cultura organizacional das empresas que desejam implantar uma nova forma de trabalho, especialmente para aquelas que querem abandonar velhos hábitos, está primeiramente em reconhecer que a cultura é formada por pessoas, logo é o recurso mais importante de uma organização. Portanto, se não for por meio delas, o resultado não aparecerá, pois, considerando que a cultura está inserida nos aspectos críticos da estratégia, desenvolver e envolver adequadamente as pessoas é necessidade sine qua non (sem o qual não pode ser) para que uma mudança possa ocorrer.

De qualquer modo, sempre é bom enfatizar que mudanças mais globais na cultura organizacional são investimentos para longo prazo, com períodos de avanços (aceitação) e retrocessos (resistências) se alternando, até que o ciclo da internalização se efetive com o emprego do novo valor em todos os momentos da vida organizacional. Essa assimilação, por outro lado, servirá de aprendizagem para outros tantos processos que darão suporte às inovações e às exigências de flexibilidade cultural.

Entretanto, pretende-se encurtar esse prazo o mais rápido possível por meio de novas abordagens e técnicas de gestão, a fim de antecipar os resultados que se deseja alcançar. Nesse contexto, o aprendizado das técnicas da Toyota é um dos caminhos a ser seguido. Contudo, para se construir uma cultura organizacional de uma empresa, faz-se necessária a integração das técnicas gerenciais, bem como o envolvimento adequado das pessoas.

Portanto, quando as técnicas de gestão forem aplicadas integradas umas com as outras, um sistema será formado. Também quando o sistema for praticado e defendido por todas as pessoas da organização, uma cultura será formada. Ver ilustração na Figura 1. 
Figura 1 - Construção de uma cultura organizacional

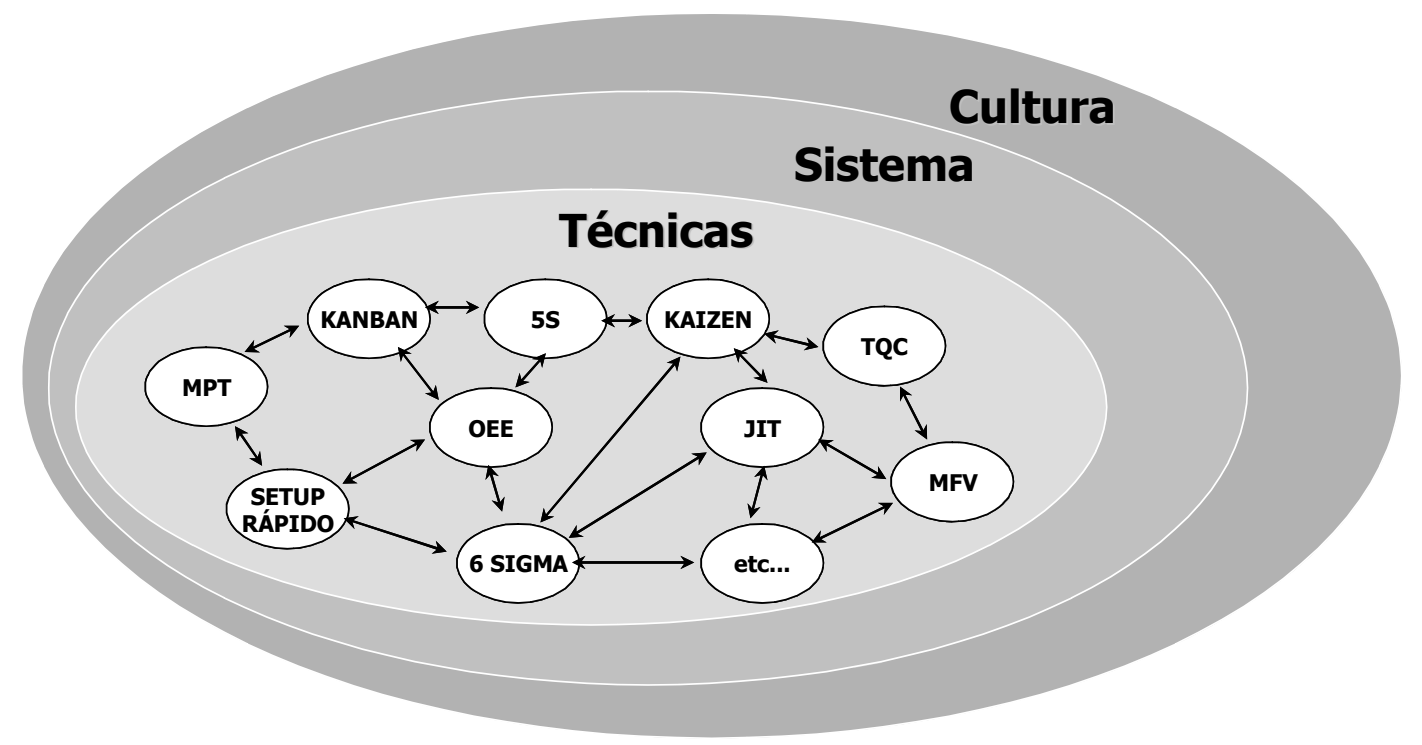

Fonte: O autor (2009).

\section{Considerações finais}

Segundo Schein (1985), a cultura organizacional é o desenvolvimento de pressupostos básicos obtidos por um grupo ao aprender como lidar com os problemas de adequação externa e integração interna e que deram resultados satisfatórios para serem considerados válidos e ensinados a novos membros como a forma correta de perceber, pensar e sentir, em relação a esses problemas.

A cultura de uma empresa passa a ser sua identidade definida como a forma em que seus colaboradores reagem frente aos problemas de adaptação, bem como a maneira de pensar, perceber e agir. Portanto, as pessoas têm papel fundamental no processo de mudança para uma empresa que deseja implantar os princípios do TPS.

O cenário atual é marcado por fortes mudanças que estão virando pelo avesso a maneira de trabalhar, produzir, atender ao cliente, criar valor e agregar riqueza. Por essas razões, a produção de bens e serviços não é mais a mesma. Aparece agora uma empresa enxuta preocupada com uma maior flexibilidade, alta produtividade, estoques baixos, exposição de problemas, menor tempo de entrega produtos e serviços, custos baixos, atividades com valor agregado e pessoas totalmente envolvidas.

Entretanto, desenvolver uma cultura organizacional que esteja alinhada com esse novo cenário e perfil organizacional é fundamental não somente para o TPS, mas também, como estratégia competitiva frente à concorrência com o intuito de sobreviver nesse novo ambiente. Desta forma, a cultura corporativa deve reforçar a estratégia e o projeto estrutural de que a organização 
necessita para ser eficaz em seu ramo de atividade. Se o ambiente externo exige flexibilidade e responsabilidade, a cultura deve incentivar a adaptabilidade (MINTZBERG; QUINN, 2006).

A mudança na cultura organizacional das empresas que desejam implantar o TPS é necessidade sine qua non, especialmente para aquelas que adotam um modelo de produção em massa. Entretanto, ser Lean está primeiramente em reconhecer que a cultura é formada por pessoas, que estas são os recursos mais importantes de uma organização e, se não for através delas, o resultado não aparecerá.

Segundo Hines e Taylor (2000), os operários devem estar equipados com "óculos de muda" (muda significa qualquer atividade que consome recursos e que não agrega valor aos clientes), tornando-os habilitados a enxergar as perdas, isto é, desenvolver uma cultura que os encorajem a eliminá-las, uma vez identificadas. Portanto, considerando que a cultura está inserida nos aspectos críticos da estratégia, desenvolver as pessoas será uma variável de suma importância para a mudança acontecer (MINTZBERG; QUINN, 2006).

Portanto, o ponto fundamental do TPS está na disseminação das técnicas aqui apresentadas em práticas utilizadas por todas as pessoas da organização, ou seja, de maneira sinérgica para criar um sistema de alta qualidade que fabrica produtos no ritmo que o cliente deseja e sem desperdícios.

Entretanto, cada técnica possui sua característica individual, crítica e necessária para o sucesso do desenvolvimento do modelo de gestão, porém nenhuma delas pode estar sozinha e ser esperado que este atinja o mesmo nível de desempenho se combinadas. Cada uma contém um conjunto de princípios, as quais, operando em conjunto, irão desenvolver o ambiente que deseja construir.

Conclui-se, portanto, que as técnicas gerenciais aqui apresentadas fazem parte de um conjunto de pressupostos básicos, necessários para a formação de um ambiente interno que contribuirá para o desenvolvimento de uma filosofia que resulta de um sistema praticado e defendido por todas as pessoas da organização. Somente através de uma interação efetiva entre lideres e liderados será possível entender os segredos do TPS e re-inventar as práticas existentes no sentido de quebrar os antigos paradigmas que travam o processo de transformação rumo a empresa enxuta.

\begin{abstract}
Because of great success and results by Toyota even with the recent industrial leadership that overstep the powerful General Motors - GM, research are made in order to understand the Toyota Production System - TPS that is today benchmarking for the competitors, as well as the enterprises from different sectors. Therefore, the objective that conduct this paper is in the following question: what are the management techniques of Toyota Production System?. The methodology of this paper adopts a literature review research. It is an analysis about the TPS evolution, showing some of the principal management techniques. The result is the contribution to understand the growing of the
\end{abstract}


organization cultural, in order to indicate a way to be followed by others enterprises that want to reply the management model. The conclusion is that the management techniques here demonstrated are part of a basic precondition needed to format a philosophy that results in a system pratice and defended by every people of the organization, because only by the interplay of management techniques beyond peoples, it will be possible to reply a culture seemed by Toyota.

Key-words: toyota production system, lean manufacturing, management techniques

\section{Referências}

GIL, A. C. Como Elaborar Projetos de Pesquisa. São Paulo: Atlas, 1996.

HINES, P.; TAYLOR, D. Guia para implementação da Manufatura Enxuta - "Lean Manufacturing”. São Paulo: IMAM, 2000.

LIKER, J. K. O Modelo Toyota: 14 Princípios de Gestão do Maior Fabricante do Mundo. Porto Alegre: Bookman, 2005.

MINTZBERG, H.; QUINN, J. B. O processo da estratégia. 4. Ed. Porto Alegre: Bookman, 2006.

NORONHA, D. P.; FERREIRA, S. M. S. P. Revisões da Literatura. In: Campello, B.S., Cendón, B.v. e Kremer, J.M. Fontes de Informação para Pesquisadores e Profissionais. Belo Horizonte: Ed. UFMG, p. 191-198, 2000.

OHNO, T. O Sistema Toyota de Produção - além da produção em larga escala. Porto alegre: Bookman, 1997.

PORTER, M. E. Competição: Estratégias Competitivas Essenciais. Harvard School Business Press, 1999.

SHAH, R.; WARD, P. T. Lean manufacturing: context, practice bundles, and performance. Journal of operations Management, v. 335, p. 1-21, 2002.

SCHEIN, E. H. Organizational Culture and Leadership. São Francisco: Jossey-Bass, 1985.

SHINGO, S. O Sistema Toyota de Produção do ponto de vista da Engenharia de Produção. Porto Alegre: Bookman, 1996.

WOMACK, J. P.; JONES, D. T. e ROOS, D. A máquina que mudou o mundo. 14. ed. Rio de Janeiro: Campus, 1992.

WOMACK, J. P.; JONES, D. T. A Mentalidade Enxuta nas Empresas. $3^{\text {a }}$ ed. Rio de Janeiro: Campus, 2004.

Dados dos autores:

Nome completo: Marcelo Augusto Oliveira da Justa

Filiação institucional: Universidade Federal do Amazonas - UFAM

Departamento: FT - Faculdade de Tecnologia

Função ou cargo ocupado: Mestre em Engenharia de Produção

Endereço completo para correspondência (bairro, cidade, estado, país e CEP): Rua 30 casa 19, QA37, Conj. Jardim de Versailles, Bairro Planalto, Manaus - Amazonas - Brasil, CEP 69044-770

Telefones para contato: (92) 3656-0012 ou (92) 8179-2273

e-mail: marcelo.justa@bol.com.br 
Nome completo: Prof ${ }^{0}$. Dr. Nilson Rodrigues Barreiros

Filiação institucional: Universidade Federal do Amazonas - UFAM

Departamento: FT - Faculdade de Tecnologia

Função ou cargo ocupado: Coordenador do Curso de Engenharia de Produção

Endereço completo para correspondência (bairro, cidade, estado, país e CEP): Av. General Rodrigo Otávio Jordão Ramos, 3000, Bairro Aleixo, Manaus - Amazonas - Brasil, CEP 69077-000

Telefones para contato: (92) 3647-4418 / 3647-4432

e-mail: nilbarr@ufam.edu.br

Recebido para publicação em: 12/01/2009

Aceito para publicação em: 02/03/2009 